\title{
A mensuração do potencial interno de desenvolvimento de um Arranjo Produtivo Local: uma proposta de aplicação prática
}

\author{
Measurement of the internal development potential of a cluster: a proposal for a \\ practical application
}

Marcos Junior Marini ${ }^{[0]}$, Christian Luiz da Silva ${ }^{[b]}$

\begin{abstract}
[a] Doutor em Tecnologia (UTFPR), professor do Programa de Pós-Graduação em Desenvolvimento Regional (PPGDR), Universidade Tecnológica Federal do Paraná (UTFPR), Pato Branco, PR - Brasil, e-mail: marini@utfpr.edu.br ${ }^{[b]}$ Doutor em Engenharia de Produção (UFSC), professor do Programa de Pós-Graduação em Tecnologia (PPGTE), coordenador do Programa de Pós-Graduação em Planejamento e Governança Pública, Universidade Tecnológica Federal do Paraná (UTFPR), Curitiba, PR - Brasil, e-mail: christiansilva@utfpr.edu.br
\end{abstract}

\section{Resumo}

Nas últimas décadas do século XX intensificaram-se as discussões sobre a importância das ações conjuntas realizadas pelos agentes participantes de aglomerações industriais, como ocorre nos Arranjos Produtivos Locais, principalmente nas políticas públicas relacionadas ao desenvolvimento local ou regional. Nesse contexto, o artigo objetiva propor uma metodologia para mensurar o potencial interno de desenvolvimento de um Arranjo Produtivo Local. A análise das especificidades territoriais presentes nesse cenário gerou um arcabouço metodológico formado por critérios e subcritérios, os quais originaram o Índice do Potencial Interno de Desenvolvimento de um Arranjo Produtivo Local (IPID). Os procedimentos metodológicos da pesquisa basearam-se no método de estudo de caso, em uma abordagem quantiqualitativa, com a aplicação da proposta metodológica no APL de Confecções do Sudoeste do Paraná. Em síntese, a mensuração do IPID demonstrou tecnicamente as condições internas de desenvolvimento desse APL, com os resultados revelando que se trata de um APL com um potencial interno de desenvolvimento muito bom, atingindo praticamente $70 \%$ da escala possível para o IPID. Ademais, nessa mensuração, o capital social e a governança local do APL apresentaram os melhores resultados. Como encaminhamento, sugere-se um maior envolvimento dos agentes no plano de ações do APL, bem como a ampliação da participação nas práticas cooperativas.

Palavras-chave: Arranjos Produtivos Locais. Planejamento urbano e regional. APL de Confecções do Sudoeste do Paraná. Políticas públicas.

\section{Abstract}

In the last decades of the twentieth century, discussions about the importance of joint actions undertaken by participant agents of industrial agglomerations were intensified, as it occurs in clusters, especially in public policies related to local or regional development. In this context, this study proposes a methodology to measure the internal development potential of a cluster. The analysis of territorial specificities present in this scenario 
generated a methodological framework composed of criteria and sub-criteria, which originated the Index of Internal Development Potential of a Cluster (IPID). The methodological procedures of the survey were based on the method of case study, using a quantitative and qualitative approach, applied to the Clothing Cluster of Southwestern Paraná. In summary, the measurement of the IPID technically demonstrated the internal development conditions of the cluster studied. Results showed that the cluster presents a very good internal development potential, reaching almost 70\% of the possible range for the IPID. Moreover, in this measurement, the social capital and local governance of the cluster showed the best results. As a proposal, we suggest a greater involvement of agents in the action plan of the cluster, as well as the expansion of participation in cooperative practices.

Keywords: Clusters. Urban and regional planning. Clothing cluster of Southwestern Paraná. Public policies.

\section{Introdução}

A sociedade mundial vem vivenciando profundas transformações, principalmente a partir de meados do século XX, com a literatura apontando alguns fatores como responsáveis por essas mudanças, entre os quais a globalização, os avanços das tecnologias de informação e comunicação (TICs), bem como a reestruturação do sistema produtivo mundial, com a passagem do modo de produção em massa para um regime de especialização flexível (ALBUQUERQUE, 1998; BENKO, 1999; CASTELLS, 1999).

Segundo Casarotto Filho e Pires (1998), em um mundo globalizado e altamente competitivo, somente o associativismo e a junção de esforços possibilitam força competitiva, principalmente para as pequenas empresas. Nessa direção, Cassiolato e Lastres (2000) afirmam que o aproveitamento das sinergias coletivas geradas pelo processo aglomerativo tem possibilitado vantagens competitivas para essas empresas.

As diversas experiências internacionais das aglomerações industriais originaram uma proliferação de terminologias para esse fenômeno. No Brasil, desde o final da década de 1990 é utilizado o termo Arranjo Produtivo Local (APL), com inúmeras políticas públicas relacionando o tratamento coletivo de pequenas e médias empresas organizadas em APLs ao desenvolvimento regional (AMATO NETO, 2000; SUZIGAN, 2006; COSTA, 2010).

Considerando a importância atribuída às ações conjuntas desenvolvidas pelos agentes que formam um APL e, ainda, a necessidade de se considerar as especificidades territoriais nas quais o arranjo produtivo está localizado, incluindo elementos das dimensões espacial, cultural, política e institucional, surge como questão de pesquisa: como avaliar o potencial interno de desenvolvimento de um APL? Nessa direção, este artigo tem como objetivo propor uma metodologia para mensurar o potencial interno de desenvolvimento de um Arranjo Produtivo Local a partir da análise das interações sociais desses agentes.

Com relação aos aspectos metodológicos, a pesquisa está classificada como explicativa, utilizando o método estudo de caso. A coleta e a interpretação dos dados envolvem uma abordagem quantiqualitativa, a partir de fontes primárias, acessadas com a aplicação de questionários estruturados em entrevistas realizadas em uma pesquisa de campo, bem como a partir de fontes secundárias, com dados coletados de bases estatísticas governamentais.

0 artigo está organizado em cinco seções, incluindo esta introdução. A segunda seção aborda a fundamentação teórica referente ao desenvolvimento local e aos APLs. A seção seguinte descreve a proposta metodológica e a quarta seção destina-se à discussão dos resultados de uma aplicação prática. Por fim, são apresentadas as considerações finais.

\section{Fundamentação teórica}

Esta seção apresenta a fundamentação teórica deste artigo, incluindo uma discussão sobre o 
desenvolvimento local como organização do território, abordando brevemente as correntes do desenvolvimento econômico endógeno, bem como uma contextualização envolvendo a temática dos Arranjos Produtivos Locais (APLs).

\section{Desenvolvimento local como organização territorial}

Como um dos pilares propostos para esta pesquisa, as Teorias do Desenvolvimento Econômico Endógeno integram o escopo das discussões, a partir da visão do desenvolvimento local como organização territorial. Amaral Filho (2001) chama esse processo de movimento de endogeneização, destacando que esse novo paradigma de desenvolvimento local ou regional surgiu na década de 1980, com as chamadas correntes do desenvolvimento econômico endógeno, a partir de três principais estratégias: distrito industrial; milieu innovateur (ambiente inovador); cluster.

Nessa direção, observa-se que os distritos industriais apresentam como principal característica a geração de vantagens aglomerativas que se originam de externalidades marshallianas (AMARAL FILHO, 2001). Na segunda estratégia, milieu innovateur, desenvolvida pelo GREMI (Groupe de Recherche Européen sur les Milieux Innovateurs), o meio, ou seja, as características dos contextos locais (ambiente) implicam na formação de redes de relacionamento e na geração de inovações, representando esse um modelo neo-schumpeteriano (IGLIORI, 2001; CAVALCANTE, 2008). Com relação à estratégia do cluster ou agrupamento, destaca-se que está relacionada com as vantagens competitivas oriundas da concentração geográfica de empresas, explicitamente associadas ao conceito de competitividade nesses aglomerados (PORTER, 1998).

Ainda nessas discussões encontram-se a Nova Sociologia Econômica (NSE), a qual considera a importância das relações sociais para o desenvolvimento dos territórios (GRANOVETTER, 2003), bem como a Teoria da Nova Geografia Econômica (NGE), baseada na análise das forças centrífugas e centrípetas desses espaços (KRUGMAN, 1998).

Em síntese, todas essas abordagens são sustentadas pela visão de um novo modelo de desenvolvimento, no qual as questões territoriais orientam a prática. De acordo com Boisier (2001, p. 14):

[...] o desenvolvimento endógeno é produzido como resultado de um forte processo de articulação de atores locais e de variadas formas de capital intangível, num projeto político coletivo de desenvolvimento do território em questão.

Por conseguinte, o movimento de endogeneização amplia o papel dos atores ou agentes locais quanto à tomada de decisão, logo "[...] a organização territorial deixou de ter um papel passivo para exercer um papel ativo diante da organização industrial." (AMARAL FILHO, 2001, p. 262). Assim, o desenvolvimento passa a estar enraizado nas condições locais e na força dos seus agentes, incluindo-se atributos como: organização social, participação, empoderamento, coordenação das iniciativas locais, reconhecimento e valorização local.

Nessa perspectiva de desenvolvimento local como organização territorial, Benko (1999) chama a atenção para a necessidade de modelos que projetem novos territórios com base nos recursos presentes no tecido humano e social, inclusive a importância do protagonismo local. Ademais, Albuquerque (1998) enfatiza que para a formação de um território socialmente construído é necessário compreender as questões históricas, culturais, políticas e institucionais.

Corroborando com o debate, Albagli (2004) afirma que a comunicação entre os indivíduos pertencentes a um território, a partir de um processo cumulativo de troca de experiências, caracterizase como o principal atributo social na formação da territorialidade. Diante do exposto, é possível afirmar que os APLs podem ser considerados como uma das estratégias de organização territorial para o processo de desenvolvimento local. Com esse encaminhamento, a próxima subseção aborda essa temática.

\section{Arranjos Produtivos Locais}

0 processo de endogeneização implicou na valorização territorial, com as teorias do desenvolvimento econômico endógeno destacando o papel 
da articulação desses agentes em ações integradas e conjuntas. Nesse sentido, a literatura apresenta diversos exemplos clássicos de aglomerações produtivas, como o complexo de alta tecnologia do Vale do Silício, nos Estados Unidos; os distritos industriais da Terceira Itália; sistemas produtivos locais na França, Alemanha e Reino Unido; as redes de empresas no Japão, Coréia e Taiwan, entre outros.

Contudo, mesmo com a heterogeneidade desses casos, é possível destacar algumas características comuns para essas aglomerações produtivas locais, entre as quais: integram um conjunto de empresas com especialidade produtiva; são constituídas principalmente por pequenas e médias empresas; possuem diversas instituições de apoio (agentes econômicos, sociais, políticos); apresentam vínculos interativos entre os agentes; buscam ganhos de eficiência coletiva gerados pelo processo aglomerativo; promovem práticas cooperativas (MARINI et al., 2012).

Em continuidade, Marini et al. (2012) destacam alguns componentes que constituem a base das discussões sobre os APLs, entre os quais: externalidades, ações conjuntas, capital social, governança local e políticas públicas. Logo, optouse por apresentar uma breve contextualização para cada um desses componentes.

A temática das externalidades (economias externas) remete ao final do século XIX, com os estudos clássicos de Alfred Marshall envolvendo os distritos industriais de cutelaria na Inglaterra e as vantagens oriundas desse processo aglomerativo. 0 autor apresenta as chamadas externalidades marshallianas: um conjunto de trabalhadores qualificados para a atividade econômica; o acesso a fornecedores de bens e serviços; a rápida disseminação de novos conhecimentos (MARSHALL, 1982). Logo, as externalidades correspondem a fatores externos às empresas, mas oriundas do espaço geográfico em que estão inseridas.

Corroborando com essas discussões, Schmitz (1997) argumenta que as externalidades marshallianas são importantes, porém, incidentais ou passivas. Assim, esse autor sugere a necessidade de criar ações conjuntas, a partir da junção dos esforços e ações entre os diversos agentes, o que possibilita a formação da eficiência coletiva (SCHMITZ, 1997).

Diante do exposto, evidencia-se uma estreita vinculação do APL com as condições locais, a partir dos aspectos socioculturais que formam esse tecido produtivo. Para Albagli e Maciel (2003, p. 434),
[...] a emergência do tema do capital social expressa o reconhecimento de que, para melhor compreender e intervir sobre a dinâmica econômica, é preciso considerar a estrutura e as relações sociais em que ela ocorre.

Portanto, ressalta-se que o capital social corresponde às relações entre os grupos e redes, a partir de normas e confiança que as pessoas têm em propósitos produtivos, o que facilita as ações coordenadas (PUTNAM, 1996; WOOLCOCK et al., 2003).

Ainda nesse debate, é importante destacar que a necessidade do fortalecimento dos laços entre os agentes para a realização das ações conjuntas implica diretamente na existência de mecanismos institucionais e de governança para a coordenação dessas ações propostas no APL, visando garantir o estabelecimento de objetivos comuns e o aproveitamento das sinergias coletivas (AMARAL FILHO, 2011).

Nessa direção, ressalta-se que um APL inclui além das empresas do APL outros agentes como: universidades e centros tecnológicos, associações de classe, instituições públicas e órgãos governamentais, instituições financeiras, órgãos de apoio e fomento. Logo, evidencia-se que essa rede complexa e heterogênea necessita de formas estáveis de governança local, com o estabelecimento de práticas democráticas a partir da intervenção das diferentes categorias de agentes (CASSIOLATO; SZAPIRO, 2003).

Complementando essa contextualização envolvendo os principais componentes de um Arranjo Produtivo Local torna-se necessário identificar o papel das políticas públicas, que têm nas esferas governamentais (municipais, estaduais e federais) seus agentes de apoio para a promoção e o fortalecimento das condições locais.

Em síntese, as políticas públicas devem encontrar sintonia com as ações da governança local do APL, fortalecendo o capital social e contribuindo com a geração de externalidades locais (SUZIGAN, 2006; MARINI et al., 2012). Logo, o maior desafio passa pelo desenho de políticas públicas capazes tanto de impulsionar o desenvolvimento econômico como de promover a inclusão social da população (SOUZA, 2006). 
Diante desse quadro teórico, revela-se a necessidade de mobilização endógena dos agentes territoriais a partir do estabelecimento de um projeto coletivo como elemento sinérgico para o planejamento regional. Albuquerque (1998, p. 57) afirma que

[...] é assim que se constroi o desenvolvimento, a partir do fortalecimento do território, isto é, da mobilização produtiva e empresarial da própria sociedade local em torno de um projeto de desenvolvimento territorial sustentável e equitativo.

\section{Metodologia para a mensuração do potencial interno do APL}

A partir do objetivo deste artigo, esta seção apresenta o detalhamento da proposta metodológica para a mensuração do potencial interno de desenvolvimento de um Arranjo Produtivo Local (APL), incluindo uma revisão inicial sobre as metodologias para esse cenário em discussão. A seguir é apresentada a metodologia proposta neste artigo, incluindo-se breve descrição dos métodos de análise de redes sociais e análise multicritério.

Com relação à revisão da literatura sobre metodologias para essa proposta de discussão, Marini et al. (2012) desenvolveram um estudo para identificar e analisar comparativamente possíveis metodologias no âmbito dos APLs, a partir de uma pesquisa bibliográfica em repositórios acadêmicos. De acordo com esses autores, a pesquisa demonstrou a inexistência de metodologias para análise interna dos arranjos produtivos, revelando, ainda, uma diversidade de abordagens para a temática dos APLs, com os estudos relacionando-se a uma discussão específica, individualizada e fragmentada (MARINI et al., 2012).

Ainda nesse contexto de discussões, cabe destacar que a literatura aponta para uma proposta metodológica que visa especificamente à identificação, delimitação geográfica e caracterização estrutural de sistemas locais de produção (SLPs) ou Arranjos Produtivos Locais (APLs), a qual foi desenvolvida pelos pesquisadores Suzigan, Furtado,
Garcia e Sampaio, em um estudo realizado no estado de São Paulo (SUZIGAN et al., 2004).

Essa proposta metodológica utiliza o coeficiente de Gini locacional (GL) e o quociente locacional (QL), relacionando o emprego na atividade econômica em relação ao total de empregos no conjunto das atividades da região avaliada, a partir de informações da base de dados da Relação Anual de Informações Sociais do Ministério do Trabalho e Emprego (MTE/RAIS) e do Instituto Brasileiro de Geografia e Estatística (IBGE).

Adicionalmente são aplicados alguns filtros e critérios estatísticos para a definição de variáveis de controle. Dessa forma, a compilação desse conjunto de informações possibilita a classificação dos arranjos produtivos, considerando-se a sua participação no emprego do setor para a região definida, bem como a sua importância para o desenvolvimento local. Em síntese, os APLs são enquadrados na seguinte tipologia: Núcleo de Desenvolvimento Setorial/Regional, Vetor de Desenvolvimento Local, Vetor Avançado, Embrião de arranjo produtivo (SUZIGAN et al., 2004).

Ainda nessas discussões, ressalta-se que Leite Filho e Antonialli (2011) também apresentam uma proposta para agrupar os APLs a partir de indicadores como: Gini locacional (GL), quociente locacional (QL), quantidade de empregos, coeficiente de participação e número de estabelecimentos. A proposta denominada análise de agrupamentos busca expandir a análise da proposta anterior, com uma classificação baseada na seguinte tipologia: APLs iniciantes, APLs em desenvolvimento, APLs consolidados ou desenvolvidos (LEITE FILHO; ANTONIALLI, 2011).

A partir dessa contextualização inicial sobre metodologias existentes para APLs é importante observar que são propostas metodológicas específicas para identificação e classificação de arranjos produtivos a partir de indicadores quantitativos relacionados ao número de empregos e estabelecimentos de uma atividade econômica. Portanto, mesmo abordando uma discussão metodológica para APLs, não incluem o escopo de análise proposto para a metodologia apresentada neste artigo, descrita a seguir. 
Proposta metodológica: IPID'

A base teórica para a construção desta proposta metodológica denominada Índice do Potencial Interno de Desenvolvimento do Arranjo Produtivo Local (IPID) assenta-se nas discussões apresentadas anteriormente na fundamentação teórica, incluindo, ainda, a utilização dos métodos de análise de redes sociais e análise multicritério.

Nesse sentido, ressalta-se que o método de Análise de Redes Sociais (ARS) possibilita uma análise sociométrica de uma rede, identificando propriedades como: densidade da rede, nível de reciprocidade e centralidade (WASSERMAN; FAUST, 1994; SCOTT, 2000). Logo, torna-se uma importante ferramenta para a mensuração do capital social, possibilitando, assim, a análise sociométrica dos agentes participantes de um APL.

Ainda nessa contextualização inicial, convém destacar que também foi necessária a utilização de um método de análise multicritério, indicado na resolução de problemas que possuem vários objetivos simultâneos, pois possibilita a representação explícita de uma estrutura de preferências baseadas em um modelo de comparações binárias dos critérios estabelecidos para o escopo em discussão (GOMES; ARAYA; CARIGNANO, 2004).

Assim, optou-se pela utilização do método de Análise Hierárquica de Processos (AHP) desenvolvido por Thomas Saaty, o qual possibilita a definição dos pesos a serem utilizados para os critérios que formam um mesmo nível hierárquico do problema, baseando-se em uma escala de preferências atribuída ao conjunto de comparações realizadas.

Com esse encaminhamento, a utilização do método de Análise Hierárquica de Processos (AHP) implicou na estruturação hierárquica do problema para a formação da respectiva árvore de critérios, a partir da identificação dos componentes que possuem relacionamento direto com o potencial interno de um APL. Logo, definiu-se que ações conjuntas, capital social e governança local estão vinculados mais diretamente com as ações desenvolvidas no APL, enquanto externalidades e políticas públicas são fatores locacionais, ou seja, possuem maior relação com a localização geográfica do arranjo produtivo.

Em seguida foi necessário identificar os respectivos subcritérios que formam cada um dos três critérios selecionados (ações conjuntas, capital social e governança local), os quais serão utilizados para a composição final de cada critério, a serem detalhados adiante. A Figura 1 apresenta a estruturação hierárquica definida na composição dessa proposta metodológica para a mensuração do Índice do Potencial Interno de Desenvolvimento do Arranjo Produtivo Local (IPID).

Como pode ser visto na elipse situada na parte inferior da Figura 1, o conjunto de subcritérios possui relacionamento direto com os condicionantes territoriais, a partir das respectivas interações com elementos que estão presentes nas dimensões espacial, cultural, política e institucional. Ainda nessa figura observa-se que a proposta metodológica é formada por três critérios e 19 subcritérios, incluindo-se a inovação transversalmente em cada um dos três critérios, como pode ser visto no último subcritério listado (inovação coletiva; capacidade inovativa; ambiente inovativo).

Ademais é importante destacar que cada subcritério é formado por um conjunto de atributos, os quais descrevem as suas propriedades (características do subcritério). Dessa forma tornase possível identificar quais elementos devem ser utilizados na mensuração e quais fontes e técnicas serão necessárias para o tratamento desses dados.

Nessa direção ressalta-se que esses atributos (indicadores ou índices) para a composição de cada subcritério foram selecionados com base nos orientadores básicos propostos por Bossel (1999), incluindo-se as condições referentes à: existência, eficácia, liberdade de ação, segurança, adaptabilidade, coexistência, necessidades psicológicas.

Com esse encaminhamento, o Quadro 1 apresenta a descrição do conjunto de atributos que foram selecionados para a mensuração em cada um dos subcritérios, compondo o arcabouço teóricometodológico desta proposta.

\footnotetext{
${ }^{1}$ Cabe destacar que a metodologia IPID está protegida pelas legislações de propriedade intelectual, pois integra a metodologia denominada Arranjo Produtivo Local para o Desenvolvimento Sustentável Regional (APL-DSR), a qual está depositada junto ao Instituto Nacional da Propriedade Industrial (INPI do Brasil), sob o número de depósito de invenção: BR 102012 024568-0, em 27 de setembro de 2012.
} 


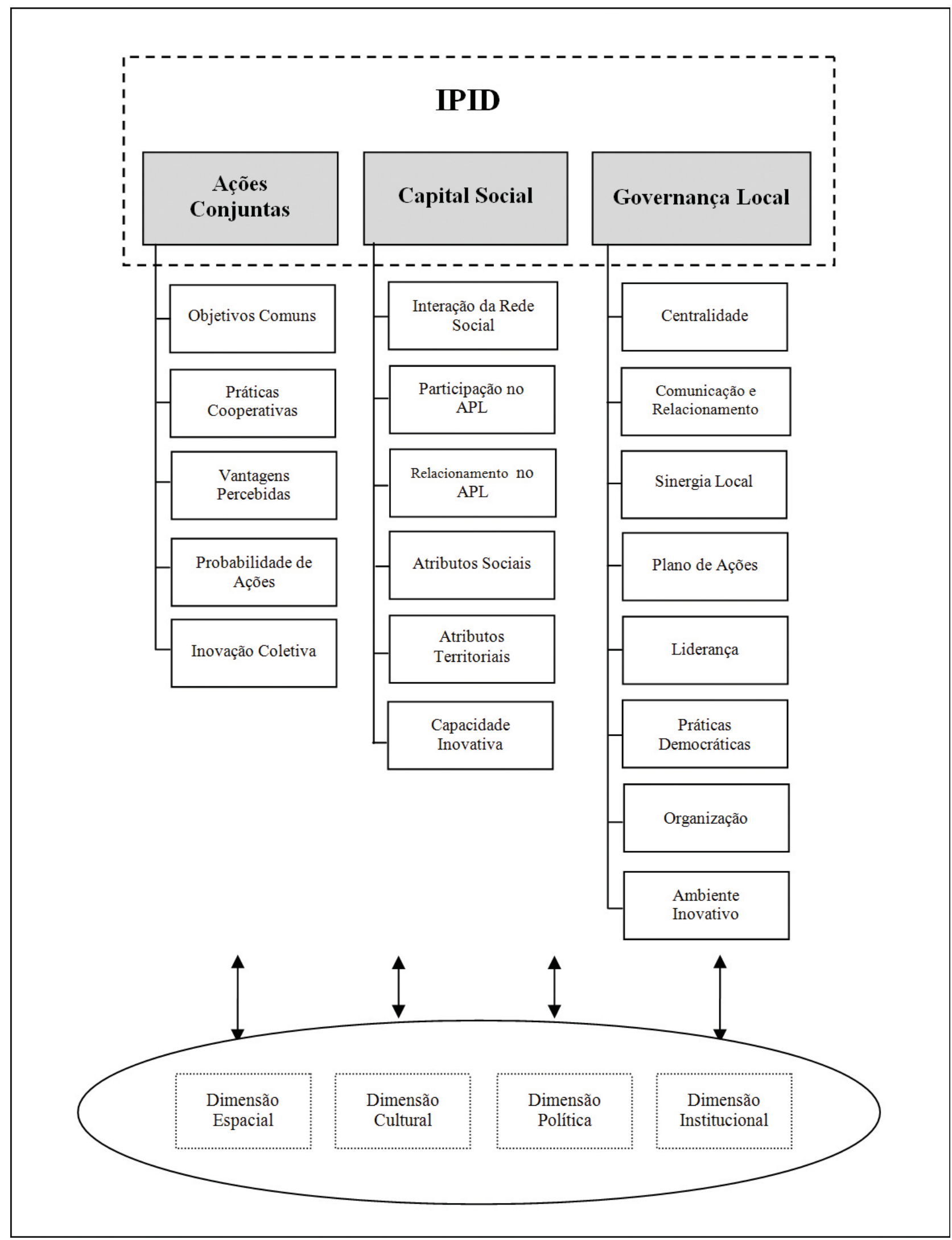

Figura 1 - Estruturação hierárquica para a mensuração do IPID Fonte: Elaborado pelos autores. 
Quadro 1 - Relação dos atributos para a composição do IPID

\begin{tabular}{|c|c|}
\hline CRITÉRIOS e SUBCRITÉRIOS & ATRIBUTOS SELECIONADOS \\
\hline \multicolumn{2}{|r|}{ Ações conjuntas } \\
\hline Objetivos comuns & Objetivos e interesses comuns entre os agentes. \\
\hline Próticas cooperativas & Participaç̦ōes em atividades conjuntas e práticas cooperativas. \\
\hline Vantagens percebidas & Percepção sobre as vantagens competitivas geradas pelas práticas cooperativas. \\
\hline Probabilidade de ações & Capacidade de formação de parcerias entre os agentes do APL. Nivel de resistência dos agentes do APL. Intenções de ampliação das parcerias. \\
\hline Inovação coletiva & Práticas inovativas em cooperação. Potencial para projetos de inovação coletiva. \\
\hline \multicolumn{2}{|r|}{ Capital social } \\
\hline Interação da Rede Social & Nível de densidade e reciprocidade entre os agentes participantes do APL. \\
\hline Participação no APL & Identificaçã̃o da variação no tamanho do APL. Participaç̧ão dos agentes nas reuniões do APL. \\
\hline Relacionamento no APL & Nível de relacionamento entre os agentes. Participaç̃õo em encontros informais. \\
\hline Atributos sociais & $\begin{array}{l}\text { Avaliaccão de atributos sociais, inclusive aspectos como: nivel de solidariedade, honestidade, confiança, cooperação e competição entre os } \\
\text { agentes. }\end{array}$ \\
\hline Atributos territoriais & 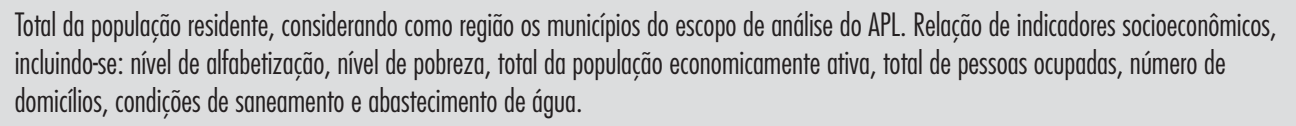 \\
\hline Capacidade inovativa & $\begin{array}{l}\text { Nível de interesse em inovacçōes e tecnologia. Percentual de empresas do APL que realizam próticas inovativas. Taxa de inovação das empre- } \\
\text { sas brasileiras do setor do APL. Gastos com atividades inovativas em relação à média setorial. }\end{array}$ \\
\hline \multicolumn{2}{|r|}{ Governança local } \\
\hline Centralidade & Identificação do nivel de centralidade dos agentes do APL. \\
\hline Comunicação e relacionamento & Funcionamento dos canois de compartithamento e troca de informaçōes entre os agentes do APL. \\
\hline Sinergia local & $\begin{array}{l}\text { Percepcão sobre o nivel de empoderamento dos agentes do APL. Capacidade de atendimento coletivo das demandas locais. Avaliação dos } \\
\text { impactos pela participação no arranjio produtivo. }\end{array}$ \\
\hline Plano de ações & Planejamento do APL e respectiva participação. \\
\hline Liderança & $\begin{array}{l}\text { Capacidade de liderança exerrida pela governanca local. Número de estabelecimentos vinculados ao arranjo produtivo. Total de estabelecimen- } \\
\text { tos da atividade econômica do APL na região considerada na análise. }\end{array}$ \\
\hline Práticas democráticas & Avaliação dos mecanismos usados na tomada de decisão. Percepç̃o sobre tratamento diferenciado e privilégios na condução do APL. \\
\hline Organização & $\begin{array}{l}\text { Agenda e formalizaccão das reuniões do APL. Geração de documentaçã̃o e compartihhamento das decisões com o conjunto de agentes. Nível } \\
\text { de interação com outros arranjos produtivos. }\end{array}$ \\
\hline Ambiente inovativo & Avaliaç̦̃o dos mecanismos de acompanhamento das condiç̄ōes do mercado visando a formaç̦ão de sinergias para um umbiente inovativo. \\
\hline
\end{tabular}

Fonte: Elaborado pelos autores.

Com relação à origem dessas informações, a proposta metodológica baseia-se na utilização de fontes primárias e secundárias. As fontes secundárias são bases de dados governamentais, incluindo-se: Ministério do Trabalho e Emprego/Relação Anual de Informações Sociais (MTE/RAIS), Instituto Brasileiro de Geografia e Estatística (IBGE), Pesquisa de Inovação Tecnológica (PINTEC).

Para as fontes primárias optou-se pela definição de questionários estruturados, os quais devem ser aplicados em entrevistas realizadas com o conjunto de agentes participantes do arranjo produtivo em análise, ou seja, envolver estritamente aqueles sujeitos que estão vinculados diretamente ao APL. Assim, busca-se a ampliação do espaço investigativo e o atendimento aos propósitos previstos para essa mensuração, incluindo-se na pesquisa de campo: governança local do APL, empresários do APL, poder público municipal, agentes de apoio (exemplos: universidades e centros de pesquisa, agência de desenvolvimento, Sebrae, Senai/Sesi, instituições financeiras e de crédito, entre outros).

A partir desse conjunto de informações apresentadas no Quadro 1 torna-se possível a realização 
de algumas operações aritméticas, por exemplo, cálculo da média aritmética simples do respectivo conjunto de atributos de um subcritério ou, ainda, a aplicação de média ponderada de acordo com as definições metodológicas, o que gera a composição final de cada um dos subcritérios da metodologia.

Adicionalmente é necessária a normalização desses valores para a escala de zero até um $(0$ 1), com três casas decimais de arredondamento. Em seguida, para cada um dos critérios utilizados (ações conjuntas, capital social e governança local) é aplicada a fórmula da média aritmética simples do conjunto de subcritérios pertencentes ao seu escopo, obtendo-se o valor final do critério, também em escala de zero a um (0-1), com três casas decimais.

Após o tratamento desses dados, a proposta metodológica prevê a aplicação do método AHP com a formação de uma matriz de decisão quadrada, gerada pela comparação par a par dos respectivos critérios, a partir da aplicação de um instrumento específico para a coleta desses dados junto aos empresários do APL. Como resultado dessa compilação, obtém-se os pesos para cada um dos critérios selecionados na proposta metodológica.

Para concluir a aplicação do método AHP, é necessária a ponderação dos valores de cada um dos critérios (ações conjuntas, capital social, governança local) com os respectivos pesos calculados anteriormente, gerando-se o Índice do Potencial Interno de Desenvolvimento do Arranjo Produtivo Local (IPID). Cabe destacar que esse índice estará situado na faixa entre zero e um (0-1), com três casas decimais, e quanto mais próximo de um, melhor será o potencial interno de desenvolvimento do APL analisado.

\section{Aplicação prática: análise e discussão dos resultados}

Com o objetivo de validar as premissas estabelecidas para a proposta metodológica de mensuração do potencial interno de desenvolvimento de um APL (IPID), esta seção apresenta os resultados e as discussões referentes a uma aplicação prática da metodologia, a qual foi conduzida no APL de Confecções do Sudoeste do Paraná.

Como contextualização inicial, ressalta-se que o APL de Confecções do Sudoeste do Paraná é um arranjo produtivo localizado na mesorregião sudoeste do estado do Paraná, com uma abrangência regional, incluindo empresas situadas em 28 municípios. Em sua constituição predominam pequenas empresas, as quais fabricam principalmente produtos da linha moda masculina, jeans e modinha feminina (SINVESPAR, 2006).

Um marco importante na trajetória histórica dessa aglomeração industrial ocorreu ao ano de 2005, quando o sindicato regional das indústrias do setor de confecções e outros parceiros instituíram o APL, o qual foi reconhecido no mesmo ano pela Rede Paranaense de Apoio aos Arranjos Produtivos Locais (REDE APL PR) e, no ano de 2008, pelo Grupo de Trabalho Permanente (GTP-APL) em nível federal.

A condução desse APL ocorre a partir de um grupo gestor, o qual possui uma estrutura de governança local que inclui diversos agentes, sob a presidência do sindicato regional. Cabe ressaltar também que o grupo gestor realiza reuniões periódicas com a participação dos agentes, visando planejar e acompanhar as ações do APL (SINVESPAR, 2006).

Após essa breve contextualização, encaminhamse as discussões referentes à aplicação da proposta metodológica. Assim, considerando a abrangência regional desse APL, foi necessária a aplicação de alguns filtros, a partir de um recorte metodológico que possibilitasse a seleção de uma amostra significativa para a pesquisa de campo.

Com esse encaminhamento, a seleção dos municípios considerou a representatividade dos empregos na atividade econômica do APL, bem como a evolução na geração de novos postos de trabalho nos últimos anos. Logo, foram selecionados os seguintes municípios ${ }^{2}$ para a amostra: Ampére, Coronel Vivida, Dois Vizinhos, Flor da Serra do Sul, Francisco Beltrão, Mangueirinha, Nova Esperança do Sudoeste, Nova Prata do Iguaçu, Pato Branco, Salto do Lontra, Santa Izabel do Oeste e Santo Antônio do Sudoeste.

Adicionalmente, ressalta-se que a pesquisa de campo totalizou 60 entrevistas, realizadas entre $1^{\text {o }}$

\footnotetext{
${ }^{2}$ Esses municípios representaram 80,8\% do total dos empregos dessa atividade econômica na região desse APL. Logo, corresponde a uma amostra condizente para o universo proposto nesta pesquisa.
} 
Quadro 2 - Resultados obtidos com a apuração dos critérios e subcritérios

\begin{tabular}{|c|c|c|}
\hline CRITÉRIO & SUBCRITÉRIO & $\begin{array}{l}\text { VALOR' } \\
\end{array}$ \\
\hline \multirow{5}{*}{ AÇ̃̃ES CONJUNTAS } & Objetivos comuns & 0,770 \\
\hline & Práticas cooperativas & 0,568 \\
\hline & Vantagens percebidas & 0,658 \\
\hline & Probabilidade de ações & 0,827 \\
\hline & Inovaç̃óo coletiva & 0,330 \\
\hline & $<$ Valor final - AC̣ÕES CONJUNTAS > 0,631 & \\
\hline \multirow{7}{*}{ CAPITAL SOCIAL } & Interaç̃õo da Rede Social & 0,657 \\
\hline & Participaç̦̃o no APL & 0,615 \\
\hline & Relacionamento no APL & 0,475 \\
\hline & Atributos sociais & 0,732 \\
\hline & Atributos territoricis & 0,887 \\
\hline & Capacidade inovativa & 0,767 \\
\hline & $<$ Valor final - CAPITAL SOCIAL >0,689 & \\
\hline \multirow{9}{*}{ GOVERNANÇA LOCAL } & Centralidade & 0,833 \\
\hline & Comunicação e relacionamento & 0,740 \\
\hline & Sinergia local & 0,713 \\
\hline & Plano de ações & 0,527 \\
\hline & Liderança & 0,574 \\
\hline & Práticas democráticas & 0,867 \\
\hline & Organização & 0,611 \\
\hline & Ambiente inovativo & 0,629 \\
\hline & $<$ Valor final - GOVERNANCA LOCAL > 0,687 & \\
\hline
\end{tabular}

Fonte: Elaborado pelos autores.

Nota: 'Todos os valores apresentados nessa coluna estão na escala de zero a um (0-1).

de março e 8 de maio de 2012, a partir da aplicação de instrumentos específicos para cada categoria de agente. Em síntese, participaram as seguintes entidades: governança local do APL (presidente do APL); 33 empresas vinculadas ao APL; 12 representantes municipais (secretários municipais da área econômica); 14 agentes de apoio (Sebrae, Agência de Desenvolvimento Regional; Universidade Estadual do Oeste do Paraná, Faculdade de Pato Branco, Sinvespar, Senai/Sesi de Pato Branco e de Francisco Beltrão, Coordenadoria das Associações Comerciais da região, diretoria sindical de Ampére, diretoria sindical de Santa Izabel do Oeste, diretoria sindical de Salto do Lontra, diretoria sindical de Chopinzinho, diretoria sindical de Dois Vizinhos, diretoria sindical de Santo Antônio do Sudoeste).

A seguir, a partir da aplicação dos instrumentos para a fase de coleta dos dados, encaminhou-se a tabulação dos resultados, considerando-se as definições do arcabouço teórico-metodológico para a mensuração do IPID. 0 Quadro 2 apresenta uma síntese com a compilação dos valores obtidos para os subcritérios e critérios mensurados no APL de Confecções do Sudoeste do Paraná.

Na sequência da aplicação da proposta metodológica para a mensuração do IPID foram gerados os pesos para cada um dos critérios, a partir dos valores comparativos obtidos nas entrevistas com os empresários do APL. A ponderação e a normalização desses dados com o método AHP resultaram nos seguintes pesos: ações conjuntas, 0,08; capital social, 0,24; e governança local, 0,68. Em seguida foram gerados os índices finais dos critérios e o valor final para o Índice do Potencial Interno de Desenvolvimento do Arranjo Produtivo 
Quadro 3 - Cálculo dos índices finais da proposta metodológica

\begin{tabular}{lccc}
\hline \multicolumn{1}{c}{ CRITÉRIOS } & VALORES & PESO (AHP) & ÍNDICE DO CRITÉRIO \\
\hline Ações conjuntas & 0,631 & 0,08 & 0,050 \\
Capital social & 0,689 & 0,24 & 0,165 \\
Governança local & 0,687 & 0,68 & 0,467 \\
& & IPID $\rightarrow$ & $\mathbf{0 , 6 8 3}$
\end{tabular}

Fonte: Elaborado pelos autores.

Local (IPID). Esses resultados podem ser vistos no Quadro 3.

Uma análise quantitativa dos resultados obtidos com a aplicação da metodologia revela que se trata de um APL com um potencial interno de desenvolvimento muito bom, atingindo praticamente $70 \%$ da escala possível para o IPID. Ademais, nessa mensuração, o capital social e a governança local do APL apresentaram os melhores resultados.

Adicionalmente, torna-se interessante a análise com uma discussão mais detalhada dos indicadores mensurados, a partir de cada um dos critérios que foram considerados nesse processo de mensuração. Nessa direção, as ações conjuntas revelaram que o APL possui um bom nível de avaliação quanto à definição de objetivos comuns entre seus agentes, atingindo um pouco mais de três quartos da escala $(0,770)$, e, ainda, a probabilidade de novas ações conjuntas atingiu um nível alto $(0,827)$, o que demonstra o interesse desses agentes em práticas cooperativas. Contudo, ressalta-se que mesmo assim no momento da coleta de dados não foi observada uma participação significativa nas ações conjuntas, que atingiu um pouco mais da metade da escala $(0,568)$. Além disso, observou-se que a inovação coletiva não é uma prática comum entre os agentes desse arranjo produtivo.

É importante destacar que a literatura aponta a importância da junção de esforços do conjunto de agentes do APL, visando o aproveitamento das sinergias coletivas do processo aglomerativo, o que pode influenciar no fortalecimento e na sobrevivência do arranjo produtivo (SCHMITZ, 1997; SCHMITZ; NADVI, 1999; AMATO NETO, 2000; CASSIOLATO; LASTRES, 2000).

Com relação aos indicadores mensurados para o capital social, observa-se que os atributos territoriais atingiram a pontuação mais elevada do conjunto analisado na proposta metodológica $(0,887)$, ou seja, quase $90 \%$ da escala prevista. É importante destacar que a literatura aponta a importância desses aspectos territoriais, pois em estudos clássicos como os dos distritos industriais italianos, identificou-se a relação entre esse componente e o desempenho dessas aglomerações industriais (PUTNAM, 1996; MACIEL, 1996).

Ainda na análise do capital social, a pesquisa demonstrou que a interação da rede social pode ser considerada média, totalizando dois terços da escala $(0,657)$. Nessa direção, Woolcock et al. (2003) indicam a necessidade do fortalecimento das relações sociais, indicador que ficou abaixo do valor médio $(0,475)$.

De forma geral, cabe destacar que os atributos territoriais $(0,887)$ e sociais $(0,732)$ apontam para uma boa condição de territorialidade na base geográfica desse arranjo produtivo, contudo, como foi apresentado anteriormente, seria necessária uma maior mobilização desses agentes para a ampliação das práticas cooperativas nesse APL.

$\mathrm{Na}$ análise do critério governança local, a aplicação metodológica identificou que essa entidade desempenha um importante papel no arranjo produtivo, sendo reconhecida como um nó central nessa rede, ou seja, com boa articulação e gestão do APL. Ademais, a capacidade de comunicação e relacionamento com o conjunto de agentes do arranjo foi bem avaliada $(0,740)$, bem como a capacidade de estabelecimento de sinergia local $(0,713)$.

Outro fator muito importante nessa análise foi a indicação da forma de condução desse APL, com a governança local estabelecendo práticas democráticas $(0,867)$, o que contribui significativamente para o processo de eficiência coletiva do APL (SCHMITZ, 1997; CASSIOLATO; LASTRES, 2000). No entanto, ainda se percebe a necessidade de um maior envolvimento do conjunto de agentes no plano de ações do APL, indicador com pior avaliação nesse critério $(0,527)$.

Como síntese para essa análise, é possível afirmarse que a proposta metodológica de mensuração do Índice do Potencial Interno de Desenvolvimento do Arranjo Produtivo Local (IPID) possibilitou demonstrar tecnicamente a relação existente entre $o$ potencial interno de um APL e a avaliação positiva de alguns elementos mencionados na literatura, entre os quais: interesse dos agentes na ampliação das ações conjuntas; nível de reciprocidade; importância 
dos atributos sociais e territoriais da região do APL; busca de objetivos comuns nas ações com os demais agentes; capacidade inovativa; capacidade de articulação da governança local, demonstrando respeito e prestígio por essa instituição na condução do APL; gestão baseada em práticas democráticas para a tomada de decisão.

\section{Considerações finais}

A articulação dos agentes territoriais visando à realização de ações conjuntas e práticas inovativas tornaram-se importante mecanismo para a promoção do desenvolvimento, originando a valorização da concentração espacial de empresas, como ocorre nos Arranjos Produtivos Locais. Ademais, observase que muitas políticas públicas são direcionadas para esse contexto. Nesse sentido, o presente artigo buscou propor uma metodologia para mensurar o potencial interno de desenvolvimento de um Arranjo Produtivo Local a partir de um arcabouço teóricometodológico para a construção desse modelo.

Com esse propósito, inicialmente foi estruturada uma árvore de critérios e subcritérios, inclusive um conjunto de elementos a serem usados na mensuração do potencial interno de um APL. Em seguida foram identificadas variáveis e as respectivas formulações aritméticas e lógicas, incluindo-se a metodologia para a coleta, tratamento e ponderação desses dados, obtendo-se assim o Índice do Potencial Interno de Desenvolvimento do Arranjo Produtivo Local (IPID).

Em síntese, a aplicação da proposta metodológica no APL de Confecções do Sudoeste do Paraná validou as premissas desta pesquisa, gerando um conjunto de indicadores multidimensionais que poderão contribuir para a definição de instrumentos e ações para o APL, apoiando tanto a governança local como os formuladores das políticas públicas relacionadas a esse cenário.

Diante do exposto, ressalta-se que esta proposta metodológica representa um novo olhar sobre essas discussões, considerando características territoriais extraídas das dimensões espacial, cultural, política e institucional. Ademais, implica em um mecanismo de mensuração do potencial interno de um APL a partir de recursos endógenos do território, em uma perspectiva de análise multidimensional, integrada e sistêmica.
Como encaminhamento para trabalhos futuros, torna-se interessante a aplicação dessa proposta metodológica e do modelo de análise a diferentes contextos, incluindo APLs de diversas atividades econômicas situados em diferentes regiões. Assim será possível a construção de uma base de dados multicasos com a formação de um histórico das mensurações nos respectivos cenários.

\section{Referências}

ALBAGLI, S. Território e territorialidade. In: LAGES, V.; BRAGA, C.; MORELlI, G. (Org.). Territórios em movimento: cultura e identidade como estratégia de inserção competitiva. Rio de Janeiro: Relume Dumará; Brasília: SEBRAE, 2004. PMCid:PMC437972.

ALBAGLI, S.; MACIEL, M. L. Capital social e desenvolvimento local. In: LASTRES, H. M. M.; CASSIOLATO, J. E.; MACIEL, M. L. (Org.). Pequena empresa: cooperação e desenvolvimento local. Rio de Janeiro: Relume Dumará, 2003. PMid:12504096.

ALBUQUERQUE, F. Desenvolvimento econômico local e distribuição do progresso técnico: uma resposta às exigências do ajuste estrutural. Fortaleza: BNB, 1998.

AMARAL FILHO, J. A endogeneização no desenvolvimento econômico regional e local. Planejamento e Políticas Públicas, n. 23, p. 261-286, 2001.

AMARAL FILHO, J. Sistemas e arranjos produtivos locais. Planejamento e Políticas Públicas, n. 36, p. 171-212, 2011.

AMATO NETO, J. Redes de cooperação produtiva e clusters regionais: oportunidades para as pequenas e médias empresas. São Paulo: Atlas, 2000.

BENKO, G. Economia, espaço e globalização: na aurora do século XXI. São Paulo: Hucitec, 1999. PMCid:PMC1460473.

BOISIER, S. Desarrollo (local): ¿ de qué estamos hablando? In: MADOERY, O.; VÁZQUEZ BARQUERO, A. (Ed.). Transformaciones globales, instituciones y politicas de desarrollo local. Rosario: Homo Sapiens, 2001.

BOSSEL, H. Indicators for sustainable development: theory, method, applications: a report to the Balaton Group. Winnipeg: International Institute for Sustainable Development, 1999. 
CASAROTTO FILHO, N.; PIRES, L. H. Redes de pequenas e médias empresas e desenvolvimento local: estratégias para a conquista da competitividade global com base na experiência italiana. São Paulo: Atlas, 1998.

CASSIOLATO, J. E.; LASTRES, H. M. M. Sistemas de inovação: políticas e perspectivas. Parcerias Estratégicas, v. 5, n. 8, p. 237-255, 2000.

CASSIOLATO, J. E.; SZAPIRO, M. Uma caracterização de arranjos produtivos locais de micro e pequenas empresas. In: LASTRES, H. M. M.; CASSIOLATO, J. E.; MACIEL, M. L. (Org.). Pequena empresa: cooperação e desenvolvimento local. Rio de Janeiro: Relume Dumará, 2003.

CASTELLS, M. A sociedade em rede. São Paulo: Paz e Terra, 1999.

CAVALCANTE, L. R. M. T. Produção teórica em economia regional: uma proposta de sistematização. Revista Brasileira de Estudos Regionais e Urbanos, v. 2, n. 1, p. 9-32, 2008.

COSTA, E. J. M. Arranjos produtivos locais, políticas públicas e desenvolvimento regional. Brasília: Mais Gráfica, 2010.

GOMES, L. F. A. M.; ARAYA, M. C. G.; CARIGNANO, C. Tomada de decisões em cenários complexos: introdução aos métodos discretos do apoio multicritério à decisão. São Paulo: Pioneira Thomson Learning, 2004.

GRANOVETTER, M. Ação econômica e estrutura social: o problema da incrustação. In: PEIXOTO, J.; MARQUES, R. (Org.). A nova sociologia econômica: uma antologia. Oeiras: Celta Editora, 2003.

IGLIORI, D. C. Economia dos clusters industriais e desenvolvimento. São Paulo: IGLU/FAPESP, 2001.

KRUGMAN, P. The role of geography in development. In: ANNUAL WORLD BANK CONFERENCE ON DEVELOPMENT ECONOMICS, 10., 1998, Washington. Proceedings... Washington: The World Bank, 1998.

LEITE FILHO, G. A.; ANTONIALli, L. M. Proposta de classificação de arranjos produtivos locais por indicadores de identificação: um estudo multivariado. Interações, v. 12 , n. 1 , p. 53-64, 2011.

MACIEL, M. L. 0 milagre italiano: caos, crise e criatividade. Rio de Janeiro: Relume Dumará, 1996.

MARINI, M. J. et al. Avaliação da contribuição de arranjos produtivos locais para o desenvolvimento local. Biblio3W:
Revista Bibliográfica de Geografía y Ciencias Sociales, v. 17, n. 996, 2012.

MARSHALL, A. Princípios de economia: tratado introdutório. São Paulo: Abril Cultural, 1982. (Os Economistas).

PORTER, M. E. Clusters and the economics of competition. Harvard Business Review, v. 76, n. 6, p. 77-90, 1998. PMid:10187248.

PUTNAM, R. D. Comunidade e democracia: a experiência da Itália moderna. Rio de Janeiro: Fundação Getúlio Vargas, 1996. PMCid:PMC228828.

SCHMITZ, H. Collective efficiency and increasing returns. Bringhton: Institute of Development Studies, 1997. (IDS Working Paper, n. 50).

SCHMITZ, H.; NADVI, K. Clustering and industrialization: introduction. World Development, v. 27, n. 9, p. 1503-1514, 1999. http://dx.doi.org/10.1016/S0305-750X(99)00072-8

SCOTT, J. Social network analysis: a handbook. 2nd ed. London: Sage Publications, 2000.

SINDICATO DAS INDÚSTRIAS DO VESTUÁRIO DO SUDOESTE DO PARANÁ - SINVESPAR. Plano de desenvolvimento do arranjo produtivo local de confecção sudoeste do Paraná. Paraná: SINVESPAR, 2006.

SOUZA, C. Políticas públicas: uma revisão da literatura. Sociologias, v. 8, n. 16, p. 20-45, 2006.

SUZIGAN, W. (Coord.). Identificação, mapeamento e caracterização estrutural de arranjos produtivos locais no Brasil. Brasília: IPEA/DISET, 2006.

SUZIGAN, W. et al. Clusters ou sistemas locais de produção: mapeamento, tipologia e sugestões de políticas. Revista de Economia Política, v. 24, n. 4, p. 543-561, 2004.

WASSERMAN, S.; FAUST, K. Social network analysis: methods and applications. Cambridge: Cambridge University Press, 1994. http://dx.doi.org/10.1017/ CB09780511815478

WOOLCOCK, M. et al. Measuring social capital: an integrated questionnaire. Washington: The World Bank, 2003. (The World Bank Working Paper, n. 18).

Recebido: 20/09/2013 Received: 09/20/2013 Aprovado: 17/12/2013 Approved: 12/17/2013 